\title{
Study on Comparing Intrathecal Hyperbaric Bupivacaine and Isobaric Bupivacaine In Common Surgical Procedures without Adjunct.
}

\author{
Dr. Rakesh Raushan, \\ Asst.Prof. Dr Prof S. Nag HOD Anesthesiology NMCH Sasaram.
}

\section{Introduction:}

For thousands of years, pain relief could be secured only at the expense of central nervous system depression as with the use of mandragora, wine and opium in ancient china, mandragora and poppy in ancient Egypt, Rome and Greece, and atropine, opium, cocaine and hallucinogens by the Incas and ancient Peruvians.

Subarachnoid block is defined as the temporary interruption of transmission of nerve impulses produced by the injection of local anaesthetic agents in to subarachnoid space subarachnoid block is one of oldest forms of regional block and is still a very commonly used one in our country. When given to properly selected patients subarachnoid block gives a clear advantage which is difficult to duplicate with general anaesthesia for surgical procedures below the level of the umbilicus.

Advantages-

Easy, Cheap, Highly reliable, Rapidity of onset, Safe

\author{
Aim And Objectives \\ The aim of this study is to compare the hemodynamic effect and recovery between intrathecal isobaric \\ bupivacaine and hyperbaric bupivacaine in common Surgical procedures based on the following objectives: \\ 1 Systolic and diastolic blood pressures at regular time intervals \\ 2 Heart rate at regular time intervals \\ 3 Respiratory rate at regular time intervals \\ 4 Onset of sensory and motor block \\ 5 Duration of sensory and motor block
}

\section{Patient selection}

\section{Patients And Methods}

\section{Inclusion criteria}

1 Patients aged between 18 and 60 years of both genders.

2 Patients belonging to ASA physical status 1 and 2

3 Patients undergoing elective surgeries below the umbilical level under spinal anaesthesia.

Exclusion criteria

Patient with any one of the following will be excluded from this study

1 Patient refusal

2 Contraindication to spinal anaesthesia inclusive of spinal cord deformities, bleeding disorder, local infection at injection site and any pre existing neurological disorders.

3 Surgeries lasting more than 3 hours.

After the conduct of subarachnoid block the following parameters will be evaluated-

Time of onset of sensory block will be assessed as the time interval between completion of injection of local anaesthetic solution to onset of complete loss of sensation to pinprick in the anterior axillary line bilaterally Duration of sensory block-assess by two segment regression time and is defined as time interval from injection of local anaesthetic solution until maximum sensory level of sensory block has decreased by two segment.

Motor Block assessed by-

Modified bromage scale (by Breen at al)

STATISTICAL METHOD-

Student unpaired "T" test ANOVA with repeated measurement will be used.

\section{Observations And Results}

100 patients of either sex and between 18-60 years age participated in this study. Each group had 50 patients each enrolled (Group I: $\mathrm{n}=50$ and Group II: $\mathrm{n}=50$ ). 
Group I received $3 \mathrm{ml}$ of isobaric bupivacaine.

Group II received $3 \mathrm{ml}$ of hyperbaric bupivacaine.

Statistical analysis was done using the SPSS 11.5 software. The tests used for statistical analysis were the student's unpaired ' $t$ ' test and the $\chi^{2}$ test. Patients were randomized using block randomization to group I and group II.

\section{Demographics}

Demographic characteristics were similar in both groups, as shown in table 1.

Table 1: Demographic information ${ }^{\text {a }}$

\begin{tabular}{|l|c|c|}
\hline & $\begin{array}{c}\text { Group I } \\
(\mathbf{n = 5 0 )}\end{array}$ & $\begin{array}{c}\text { Group II } \\
(\mathbf{n}=\mathbf{5 0})\end{array}$ \\
\hline Age $(\mathrm{yr})$ & $41.92 \pm 9.3$ & $40.18 \pm 9.3$ \\
\hline Height $(\mathrm{cm})$ & $169.4 \pm 5.56$ & $170.18 \pm 4.48$ \\
\hline Weight $(\mathrm{kg})$ & $63.74 \pm 7.9$ & $64.86 \pm 7.62$ \\
\hline Sex (M:F) & $46: 4$ & $45: 5$ \\
\hline
\end{tabular}

$\mathrm{a}$ - values are reported as mean \pm standard deviation

The mean age for the group I was 41.92; while that for group II was 40.18. The average height (in centimeters) in both groups were $169.4 \pm 5.56$ and $170.18 \pm 4.48$. With regard to the weight (in kilogram) the values were $63.74 \pm 7.9$ and $64.86 \pm 7.62$. Group I consisted of 46 males and 4 females; whereas group II had 45 males and 5 females.

\section{Systolic Blood Pressure}

\begin{tabular}{|c|c|c|c|c|}
\hline \multirow[t]{2}{*}{$\begin{array}{l}\text { Time } \\
(\min )\end{array}$} & \multicolumn{2}{|c|}{$\begin{array}{l}\text { GROUP 1 } \\
(\mathbf{m m H g}) \\
\mathrm{N}=50\end{array}$} & \multicolumn{2}{|c|}{$\begin{array}{c}\text { GROUP 2 } \\
(\mathbf{m m H g}) \\
\mathrm{N}=50\end{array}$} \\
\hline & Mean & Standard deviation & Mean & Standard deviation \\
\hline Baseline & 136.42 & 17.32 & 128.9 & 19.01 \\
\hline 5 & 130.52 & 15.26 & 109.32 & 15.01 \\
\hline 10 & 127.18 & 18.87 & 102.94 & 16.16 \\
\hline 15 & 126.44 & 15.23 & 108.8 & 14.98 \\
\hline 20 & 124.72 & 15.08 & 111.18 & 13.14 \\
\hline 30 & 121.32 & 18.34 & 110.6 & 12.08 \\
\hline 45 & 123.86 & 15.65 & 112.2 & 11.04 \\
\hline 60 & 123.5 & 14.42 & 114.06 & 12.41 \\
\hline
\end{tabular}

\section{Diastolic Blood Pressure}

Table 3: Comparison of mean diastolic blood pressure

\begin{tabular}{|c|c|c|c|c|}
\hline \multirow[t]{2}{*}{$\begin{array}{l}\text { Time } \\
\text { (min) }\end{array}$} & \multicolumn{2}{|c|}{$\begin{array}{c}\text { GROUP 1 } \\
\text { (mmHg) } \\
\mathrm{N}=50\end{array}$} & \multicolumn{2}{|c|}{$\begin{array}{c}\text { GROUP } 2 \\
\begin{array}{c}\text { (mmHg) } \\
\mathbf{N}=\mathbf{5 0}\end{array}\end{array}$} \\
\hline & Mean & Standard deviation & Mean & Standard deviation \\
\hline Baseline & 79.96 & 7.15 & 78.34 & 9.15 \\
\hline 5 & 75.80 & 8.40 & 69.12 & 8.51 \\
\hline 10 & 76.36 & 12.61 & 66.00 & 9.10 \\
\hline 15 & 75.68 & 8.16 & 68.96 & 7.52 \\
\hline 20 & 72.16 & 9.80 & 70.38 & 8.98 \\
\hline 30 & 72.96 & 10.27 & 70.90 & 6.97 \\
\hline 45 & 72.76 & 8.96 & 70.68 & 8.03 \\
\hline 60 & 75.04 & 8.09 & 73.06 & 5.51 \\
\hline
\end{tabular}

\section{Heart Rate}

\begin{tabular}{|c|c|c|c|c|}
\multicolumn{2}{c|}{ Table 4: Comparison of mean heart rate } \\
\hline \multirow{2}{*}{$\begin{array}{c}\text { Time } \\
(\mathbf{m i n})\end{array}$} & \multicolumn{2}{|c|}{$\begin{array}{c}\text { GROUP 1 } \\
\text { N=50 }\end{array}$} & \multicolumn{2}{c|}{$\begin{array}{c}\text { GROUP 2 } \\
\text { N=50 }\end{array}$} \\
\cline { 2 - 5 } & Mean & Standard deviation & 75.06 & 12.46 \\
\hline Baseline & 77.00 & 14.64 & 72.40 & 12.71 \\
\hline 5 & 73.70 & 14.49 & 70.63 & 11.72 \\
\hline 10 & 69.95 & 14.65 & 70.81 & 11.20 \\
\hline 15 & 69.06 & 14.13 & 69.82 & 11.13 \\
\hline 20 & 67.74 & 12.43 & 68.74 & 11.64 \\
\hline 30 & 67.40 & 10.73 & 68.92 & 10.63 \\
\hline 45 & 67.00 & 10.69 & 69.56 & \\
\hline 60 & 67.42 & 10.91 & & 10 \\
\hline
\end{tabular}


Study on Comparing Intrathecal Hyperbaric Bupivacaine and Isobaric Bupivacaine In ....

\section{Respiratory Rate}

\begin{tabular}{|c|c|c|c|c|}
\multicolumn{2}{|c|}{ Table 5: Comparison of mean respiratory rate } \\
\hline \multirow{2}{*}{$\begin{array}{c}\text { Time } \\
(\text { min) }\end{array}$} & \multicolumn{2}{|c|}{$\begin{array}{c}\text { GROUP 1 } \\
\text { N=50 }\end{array}$} & \multicolumn{2}{c|}{$\begin{array}{c}\text { GROUP 2 } \\
\text { N=50 }\end{array}$} \\
\cline { 2 - 5 } & Mean & Standard deviation & Mean & 1.22 \\
\hline Baseline & 17.24 & 1.64 & 17.08 & 1.33 \\
\hline 5 & 17.24 & 1.98 & 17.08 & 1.39 \\
\hline 10 & 17.22 & 2.32 & 17.24 & 1.66 \\
\hline 15 & 17.54 & 2.43 & 16.98 & 1.37 \\
\hline 20 & 17.40 & 2.25 & 16.92 & 1.15 \\
\hline 30 & 17.10 & 2.59 & 17.20 & 1.48 \\
\hline 45 & 17.02 & 1.78 & 17.36 & 1.45 \\
\hline
\end{tabular}

\section{Discussion}

Subarachnoid block is one of the most popular techniques in our country, which has the disadvantages of sympathetic and motor block, resulting in hypotension, bradycardia and immobility. It has been a dream to produce sensory block without its accompanied complications and a major step in this path is the use of intrathecal opioids, but they are not adequate anesthetics for surgery. So local anesthetics combined with opioids are the appropriate choice. Fentanyl, a phenyl piperidine derivative and a synthetic opioid, is 100 times more potent than morphine and being more potent than morphine and being more lipophilic, has less tendency to cause late respiratory depression and hence, is more suitable especially in our country which has few monitoring facilities and a greater demand on them. There are numerous benefits of using opioids with local anesthetics for spinal vs systemic opioids in the perioperative period:

- Superior analgesia with shorter time to ambulation

- Fewer pulmonary complications

- Earlier return of bowel function

- Earlier hospital discharge rates

A decreased stress response As plain solutions are in fact, slightly hypobaric (specific gravity 1.004 at $20^{\circ} \mathrm{C}$ and 0.998 at $37^{\circ} \mathrm{C}$ ) compared to CSF (specific gravity $1.0063-1.0075$, at $25^{\circ} \mathrm{C}$ ), it was found that the sitting position would result in a greater cephalad spread. ${ }^{20}$ Under controlled clinical conditions, for example, Axelsson et $\mathrm{al}^{8}$ found that decreasing the volume injected to $2.0 \mathrm{ml}$ significantly decreased the level of anesthesia to T1011 level, but that a further decrease in volume to $1.5 \mathrm{ml}$ was not associated with a further decrease in level of anesthesia. They compared $1.5 \mathrm{ml}, 2 \mathrm{ml}, 3 \mathrm{ml}$ and $4 \mathrm{ml}$ instilled intrathecally in 40 patients undergoing urological surgery under spinal anaesthesia. Increasing the volume injected in this study was not associated with an increase in level of anesthesia ${ }^{8}$. With increasing volume there was an increase in the duration of analgesia and time to complete motor block of lower limbs decreased( $3 \mathrm{ml}-14 \mathrm{mins})$. Time to maximum cephalad spread took about 15-18 minutes in all groups.2-3 segment recession was on an average between 1.5-2 hours and the rate of regression was similar in all groups(while using $3 \mathrm{ml}$ the rate of regression was $101 \pm 15.4$ minutes to reach a $\mathrm{T}_{10}$ level). Based on this study we took $3 \mathrm{ml}$ as standard volume of bupivacaine in our study. Though we added $25 \mu \mathrm{g}$ of fentanyl to the mixture we did not find considerable difference in the results as compared to previous studies. The duration of sensory block in our study had a mean of 2.1378(hrs) which was comparable to the above results.

Meanwhile in our study, the statistical analysis showed differences between mean systolic blood pressure as well as diastolic blood pressure were significant from $5 \mathrm{~min}$ interval onwards $(p<0.05)$ between the two study groups. While isobaric bupivacaine showed hardly any drop in blood pressure,systolic blood pressure dropped after 5 minutes with a $\mathrm{P}$ value $<0.001$ and diastolic blood pressure also dropped upto 15 minutes duration in the hyperbaric group $(\mathrm{P}<0.001)$. The differences in heart rate and respiratory rates were not statistically significant. The onset of sensory and motor block in group I was delayed as compared to group II. In group I the mean onset time for sensory block was $4.7837 \pm 2.93$ (mins) while in group II it was $1.0580 \pm 0.312$ (mins) with a $\mathrm{p}$ value $<0.001$. The mean onset time for motor block in group I was $5.5449 \pm$ 2.79 (mins) while in group II it was $1.2354 \pm 0.193$ (mins) with a $\mathrm{p}$ value $<0.001$. The duration of sensory and motor block were also less in group I with mean values of $2.1378 \pm 0.644$ (hrs)and $2.8418 \pm 0.464$ (hrs) as compared to group II having $3.0952 \pm 0.268$ (hrs)and 3.3664 \pm 0.238 (hrs)respectively. Here also the p value was statistically significant. 


\section{Conclusion}

Based on this present study, we can conclude that both hyperbaric bupivacaine without adjunct and isobaric bupivacaine-without adjunct provides effective subarachnoid block for surgical procedures with the following underlying conclusions outlined:

- The isobaric bupivacaine has shown to have better "rock-steady" hemodynamic stability with least changes in systolic and diastolic blood pressures after spinal anesthesia.

- The mean onset time of both sensory and motor block is significantly delayed with the use of isobaric bupivacaine.

- Due to the delayed onset time of the isobaric bupivacaine, sedation supplementation was required in a majority of the patients.

- The duration of both sensory and motor block is lesser in the isobaric group as compared to the hyperbaric group thereby enabling quicker recovery from anesthesia possible in surgical procedures.

- Isobaric bupivacaine showed to have best results for surgeries below the umbilical $\left(\mathrm{T}_{10}\right)$ level.

- Post-operative shivering was not observed with the use of isobaric unlike the $22 \%$ cases observed after the use of the hyperbaric.

Hence, the isobaric bupivacaine can be used in spinal anesthesia for surgical procedures providing an effective subarachnoid block with minimal incidence of hemodynamic instability

\section{Bibliography}

[1]. Axelsson KH, Edström HH, WidmanGB:Spinalanaesthesia with glucose-free $0.5 \%$ bupivacaine: effects of different volumes.Br J Anaesth 1984 Mar;56(3):271-8

[2]. Alexandre Faust, Roxane Fournier, Elisabeth Van Gessel, Pierre Hoffmeyer, and ZdravkoGamulin: Isobaric vs Hypobaric Spinal Bupivacaine for total hip arthroplasty in the lateral position. AnesthAnalg 2003;97:589-94

[3]. C. O.Ogun, E. N. Kirgiz, A. Duman,S.Okesli and C. Akyurek: Comparison of intrathecal isobaric bupivacaine \pm morphine and ropivacaine \pm morphine for Caesarean delivery. British Journal of Anaesthesia2003; 90 (5): 659-64

[4]. Sergio D.Belzarena,MD: Clinical effects of intrathecally administered fentanyl in patients undergoing caeserean section. Anesthesia Analgesia 1993;74:653-7

[5]. H.Singh, J Cue, G.Gaines, A.H.Geisecke: Effect of intrathecal fentanyl on onset and duration of hyperbaric subarachnoid block. Anesthesia Analgesia 1994:78;400

[6]. Fernandez-Galinski D, Rue M, Moral V, Castells C, Puig MM: Spinal Anesthesia with bupivacaine and fentanyl in geriatric patients. Anesthesia Analgesia 1996 Sept;83(3):537-41

[7]. Chu CC, Shu SS, Liu SM: The effect of intrathecal bupivacaine with combined fentanyl in caesarean section. ActaAnesth SM 1995;33:149-154

[8]. Chambers WA, Edstrom HH, Scott DB: Effect of baricity on spinal anesthesia with bupivacaine. Br J Anesth 1981;53:279-82

[9]. Logan MR, McClure JH, Wildsmith JAW: Plain bupivacaine an unpredictable spinal anaesthetic agent. Br J Anesth; 1986:58:292-6

[10]. Pitkanen M,Haapaniemi L, Tuominen M, Rosenberg: Influence of age on spinal anesthesia with isobaric $0.5 \%$ bupivacaine.Br $\mathrm{J}$ anaesth 1984;56:279-84

[11]. Alston RP, Littlewood DG, Meek R, Edstrom HH: Spinal Anesthesia with hyperbaric bupivacaine: effects of concentration and volume when administered in the sitting position. Br J Anaesth 1988;61:144-148

[12]. Uma Srivastava, Aditya Kumar, Gandhi NK, SurekhaSaxena, DeveshDutta et al: Hyperbaric or plain bupivacaine combined with fentanyl for spinal anesthesia during cesarean delivery. Indian J Anesthesia 2004;48(1):44-46

[13]. Kalso E, Tuominen M, Rosenberg PH: Effect of posture and some CSF characteristics on spinal anesthesia with isobaric 0.5\% bupivacaine.Br J Anesth 1982;54:1179-1186

[14]. Abuzaid H, Prys-Roberts C, Wilkins DG, Terry DM: the influence of diamorphine on spinal anaesthesia induced with isobaric $0.5 \%$ bupivacaine. Anesth 93;48:492-5

[15]. Biboulet P, Deschodt J, Aubas P et al: Continuous spinal anesthesia:does low dose plain/hyperbaric bupivacaine allow performa nce of hip surgery in the elderly? RegAnesth 1993;18: 170-5

[16]. Blomqvist H, Nilsson A: Is glucose free bupivacaine isobaric/ hypobaric? RegAnesth 1989;14:195-8

[17]. Chambers WA: Intrathecal bupivacaine. Br J Anaesth 1982;54:799

[18]. Skretting P, Vaagenes P, Sundres K.O, Edstromm HH, Lind B: Comparison of hyperbaric solution of bupivacaine with amethocaine.Br J Anesth 1984;56:155

[19]. Uma Srivastava, Aditya Kumar, Gandhi NK, SurekhaSaxena, DeveshDutta et al: Hyperbaric or plain bupivacaine combined with fentanyl for spinal anesthesia during cesarean delivery. Indian J Anesthesia 2004;48(1):44-46 